\title{
Exigência Nutricional de Metionina+Cistina para Galinhas Poedeiras de Ovos Brancos e Marrons, no Segundo Ciclo de Produção. 1. Características Produtivas ${ }^{1}$
}

\author{
Breno Augusto Campolina Barbosa ${ }^{2}$, Paulo Rubens Soares ${ }^{3}$, Horacio Santiago Rostagno ${ }^{3}$, \\ Martinho de Almeida e Silva ${ }^{4}$, Luiz Fernando Teixeira Albino ${ }^{3}$, Altair Soares das Graças ${ }^{3}$
}

RESUMO - Um experimento foi realizado para estabelecer as exigências nutricionais de metionina + cistina (Met + Cis) por galinhas poedeiras de ovos brancos e marrons, no segundo ciclo de produção. Duzentas e vinte oito poedeiras Lohmann Selected Leghorn e 288 poedeiras Lohmann Brown submetidas à muda forçada na $76^{\mathrm{a}}$ semana de idade foram usadas. Foi usado delineamento experimental inteiramente casualizado. Os tratamentos consistiram de duas marcas de poedeiras e seis níveis de metionina+cistina, com seis repetições e oito aves por unidade experimental. As aves foram alimentadas com ração basal contendo $2751 \mathrm{kcal} \mathrm{EM} / \mathrm{kg}, 14,20 \% \mathrm{~PB}$ e $0,484 \%$ de metionina+cistina, suplementada com seis níveis de DL-metionina $(0 ; 0,05 ; 0,10 ; 0,15 ; 0,20$; e $0,25 \%)$. Produção de ovos (\%), massa de ovo (g/ave·dia), peso de ovo (g), conversão alimentar e consumo de ração (g/ave·dia) foram avaliados. As poedeiras leves apresentaram melhores índices de produção, massa de ovos e conversão alimentar e as semipesadas, maior peso dos ovos e consumo de ração. Os níveis crescentes de Met+Cis influenciaram produção e massa de ovos, peso médio dos ovos, consumo de ração, conversão alimentar. As exigências de metionina+cistina, estimadas por meio do modelo quadrático, foram 0,692 e 0,655\%, para poedeiras de ovos brancos e marrons, respectivamente, que correspondem ao consumo diário por ave de 0,785 e $0,779 \mathrm{~g}$ de met+cis, respectivamente. Estes resultados eqüivalem a 0,649 e $0,612 \%$ de met+cis digestível, para poedeiras de ovos brancos e marrons, respectivamente.

Palavras-chave: exigência nutricional, metionina+cistina, poedeiras de ovos brancos e marrons, segundo ciclo de produção

\section{Nutritional Requirements of Methionine+Cystine by White-Egg and Brown-Egg Layer Hens in the Second Production Cycle. 1. Productive Traits}

\begin{abstract}
An experiment was conducted to establish the nutritional requirements of methionine + cystine (Met + Cys) for whiteegg and the brown-egg layers hens in the second production cycle. Two hundred and twenty eight Lohmann Selected Leghorn and 288 Lohmann Brown laying hens were submitted to forced molting at the 76 weeks of age, were used. A completely experimental randomized experimental design was used. The treatments consisted of two egg laying strains and six Meth+Cys levels, with six replicates and eight birds per experimental unit. The birds were fed a basal diet with $2,751 \mathrm{kcal} \mathrm{ME} / \mathrm{kg}, 14.20 \% \mathrm{CP}$, and .484\% methionine+cystine, supplemented with six levels of DL-methionine $(0, .05, .10, .15, .20$, and $.25 \%)$. Egg production (\%), egg mass (g/bird·day), egg weight, feed intake (g/bird-day) and feed:gain ratio were evaluated. The white-egg layer hens presented better production index, egg mass and feed:gain ratio, and the brown-egg layer hens, better egg weight and feed intake. The increasing levels of Meth+Cys influenced the production characteristics, egg mass, average egg weight, feed intake and feed:gain ratio. The methionine+cystine requirements, estimated by quadratic model, were .692 and $.655 \%$ for white-egg and brown-egg layer hens, respectively, which correspond to a daily intake per hen of .785 and $.779 \mathrm{~g}$ of Meth+Cys, respectively. These results correspond to .649 and $.612 \%$ of digestible met + cys for the white-egg and the brown-egg layer hens, respectively.
\end{abstract}

Key Words: nutritional requirement, methionine+cystine, white-egg and brown-egg layer hens, second production cycle

\section{Introdução}

A muda forçada, prática muito antiga, tem sido utilizada com o objetivo de reduzir os custos de substituição do plantel. MYANO (1993) cita que anualmente 22 milhões de aves são submetidos à muda forçada no Brasil.
OLIVEIRA (1993) relata que, além de existirem poucos estudos sobre níveis nutricionais para o segundo ciclo, as tabelas de exigência e os manuais de marcas comerciais não fazem menções das necessidades para o segundo ciclo de produção. Portanto, ROSTAGNO et al. (1996) sugerem que novas pesquisas sejam realizadas a fim de se obter melhor

\footnotetext{
${ }^{1}$ Parte da Tese apresentada à UFV, pelo primeiro autor, como parte das exigências para obtenção do título Mestre em Zootecnia. Financiada pelaFAPEMIG

2Zootecnista e Mestre em Zootecnia pela UFV

${ }^{3}$ Professor da Universidade Federal de Viçosa - Campus UFV - 36571-000 - Viçosa, MG.

${ }^{4}$ Professor da Universidade Estadual do Norte Fluminense - Campos dos Goitacazes, RJ.
} 
conhecimento das exigências de aves em segundo ciclo de postura. Essas aves tem taxas de produção menores e produzem ovos maiores, aumentando assim a perda de ovos, pois o peso da casca não se altera e fica mais frágil. Assim, são justificadas as preocupações com a qualidade externa dos ovos, principalmente no segundo ciclo de produção.

PETERSEN et al. (1983) sugerem a redução dos níveis de metionina com o objetivo de reduzir o peso dos ovos, diminuindo, assim, os problemas de qualidade externa dos ovos; a mesma afirmação é feita por OLIVEIRA (1992).

A proteína da ração é que mais onera seus custos. A utilização da proteína depende de vários fatores, entre eles a composição aminoacítica e a digestibilidade de seus aminoácidos. A formulação de ração com base apenas na proteína bruta pode induzir a dois erros, subestimar ou superestimar o conteúdo de aminoácidos da ração, podendo, assim, reduzir o desempenho dos animais e ainda onerar os custos da ração.

Com o advento da fabricação industrial de lisina (L-lisina.HCl) e metionina (DL-metionina), vários autores têm sugerido a redução do nível de proteína bruta em rações, suplementadas por aminoácidos sintéticos (BLAIR et al., 1976; WEERDEN e SCHUTTE, 1980; e CARMO, 1981).

Os avanços genéticos das poedeiras comerciais, que cada vez se tornam mais precoces e produtivas, têm exigido revisões constantes das necessidade nutricionais das aves, a fim de se estimarem, com maior precisão, suas exigências em aminoácidos.

Portanto, a presente pesquisa foi realizada com o objetivo de estimar as exigências de metionina+cistina, para poedeiras comerciais leves e semipesadas, no segundo ano de produção, no período de 82 a 97 semanas de idade.

\section{Material e Métodos}

O experimento foi realizado na seção de Avicultura do Departamento de Zootecnia, do Centro de Ciências Agrárias da Universidade Federal de Viçosa-MG, no período de 05 de março a 16 de setembro de 1996.

Foram utilizadas 576 poedeiras, submetidas à muda forçada na $76^{\mathrm{a}}$ semana de idade, sendo 288 aves leves da marca comercial Lohmann Selected Leghorn (LSL) e 288 aves semipesadas da marca comercial Lohmann Brown (LB).

As aves foram alojadas durante o período de produção em galpão de postura, de $60 \times 9 \mathrm{~m}$, cercado apenas por telas em suas laterais, coberto com telhas de cerâmica em duas águas, com dois conjuntos de quatro fileiras de gaiolas convencionais cada, separadas por corredor central de $2 \mathrm{~m}$, sendo utilizadas apenas duas fileiras centrais de um dos conjuntos. Durante o período de produção o fotoperíodo utilizado foi de 16,5 horas por dia.

Após proceder-se à muda forçada e antes de serem submetidas às rações experimentais, as aves foram distribuídas com a finalidade de se padronizarem o peso corporal e a produção de ovos. Posteriormente, passaram por um período de sete dias de adaptação à ração experimental, seguindo-se o período experimental, que teve a duração de 16 semanas.

As aves tiveram água à vontade em bebedouros de calhade alumínio tipo V, estando este acima do comedouro.

A temperatura do ar e a umidade relativa foram mensuradas por meio de termômetros de máxima e mínima e termohigrômetro, respectivamente, instalados dentro do galpão à altura das aves. As temperaturas médias e absolutas e a umidade relativa do ar registradas durante o período experimental são apresentadas na Tabela 1.

No início do período experimental as aves tinham

Tabela 1 - Temperatura e umidade relativa média durante o período experimental Table 1 - Temperature and relative humidity $(R H)$ during the experimental period

\begin{tabular}{|c|c|c|c|c|c|}
\hline \multirow{3}{*}{$\begin{array}{l}\text { Período } \\
\text { (semana) } \\
\text { Period } \\
\text { (week) }\end{array}$} & \multicolumn{4}{|c|}{$\begin{array}{c}\text { Temperatura }\left({ }^{\circ} \mathrm{C}\right) \\
\text { Temperature }\end{array}$} & \multirow[t]{3}{*}{$\begin{array}{l}\text { UR média }(\%) \\
\text { RH mean }\end{array}$} \\
\hline & \multicolumn{2}{|c|}{$\begin{array}{l}\text { Máxima } \\
\text { Maximum }\end{array}$} & \multicolumn{2}{|c|}{$\begin{array}{l}\text { Mínima } \\
\text { Mininum }\end{array}$} & \\
\hline & $\begin{array}{l}\text { Média } \\
\text { Mean }\end{array}$ & $\begin{array}{l}\text { Absoluta } \\
\text { Absolute }\end{array}$ & $\begin{array}{l}\text { Média } \\
\text { Mean }\end{array}$ & $\begin{array}{l}\text { Absoluta } \\
\text { Absolute }\end{array}$ & \\
\hline $1(82-85)$ & 24,7 & 28,5 & 14,1 & 8,0 & 64,12 \\
\hline $2(86-89)$ & 24,2 & 29,5 & 14,1 & 6,0 & 65,62 \\
\hline $3(90-93)$ & 23,4 & 28,0 & 13,6 & 4,5 & 64,17 \\
\hline 4(94-97) & 24,8 & 32,0 & 16,1 & 8,0 & 65,21 \\
\hline
\end{tabular}


528 Rev. bras. zootec.

82 semanas de idade, correspondendo à $5^{\mathrm{a}}$ semana após o início da postura pós-muda forçada, as aves leves nesta data tinham taxa de postura de $83,19 \%$ e as aves semipesadas, $78,34 \%$.

Foi utilizado o delineamento experimental inteiramente casualisado, com seis repetições e duas marcas comerciais de poedeiras, com oito aves por unidade experimental.

Os tratamentos consistiram de ração basal com $14,20 \%$ de proteína bruta (PB), suplementada com seis níveis de DL-metionina 99\% $(0,00 ; 0,05 ; 0,10$; 0,$15 ; 0,20 ;$ e $0,25 \%$ ), resultando em rações com 0,484 ; 0,$534 ; 0,584 ; 0,634 ; 0,684 ;$ e $0,734 \%$ de metionina+cistina.

A ração basal (Tabela 2) foi formulada à base de milho e farelo de soja, para conter $2751 \mathrm{kcal}$ de $\mathrm{EM} / \mathrm{kg}, 14,20 \%$ de PB, $0,234 \%$ de metionina e $0,484 \%$ de metionina+cistina, formulada de modo a satisfazer às exigências nutricionais mínimas, exceto em metionina+cistina, segundo as recomendações de ROSTAGNO (1990).

Na suplementação de metionina foi utilizada DLmetionina com $99 \%$ de pureza, em substituição ao amido de milho, ficando, dessa forma, todas as rações isoprotéicas e isocalóricas em relação as rações basais, com total de $14,2 \%$ de PB. As rações foram fornecidas à vontade durante todo o período experimental.

As características avaliadas foram produção de ovos, massa de ovo, peso médio dos ovos, consumo de ração e conversão alimentar.

Os dados obtidos foram submetidos à análise estatística, utilizando-se o programa SAEG, desenvolvido por EUCLYDES (1983).

\section{Resultados e Discussão}

Foi observada diferença significativa $(\mathrm{P}<0,05)$ entre médias de produção de ovos das poedeiras leves e semipesadas, alimentadas com diferentes níveis de metionina+cistina na ração, sendo 78,06 para poedeiras leves e $71,18 \%$ para as poedeiras semipesadas. Os níveis de metionina+cistina também influenciaram a produção de ovos $(\mathrm{P}<0,05)$, sendo que as aves que receberam suplementação de metionina apresentaram melhores índices de produção em relação às não-suplementadas.

NARVÁEZ SOLARTE (1996), em caso semelhante, atribuiu a menor produção de ovos das aves sem suplementação de metionina à deficiência deste aminoácido. Por sua vez, a redução da produção de ovos nos maiores níveis de metionina+cistina foi
Tabela 2 - Composição percentual da ração basal Table 2 - Percentage composition of basal diet

\begin{tabular}{|c|c|}
\hline Ingrediente & Quantidade(\%) \\
\hline Ingredient & Amount \\
\hline Milho (Corn) & 67,900 \\
\hline Farelo de soja (Soybean meal) & 18,383 \\
\hline Calcário & 9,339 \\
\hline \multicolumn{2}{|l|}{ Limestone } \\
\hline Inerte (Inert) & 1,948 \\
\hline Fosfato bicálcico (Dicalcium phosphate) & 1,593 \\
\hline Sal iodado (Iodized salt) & 0,347 \\
\hline Amido de milho (Corn starch) & 0,250 \\
\hline Mist. vitamínica ${ }^{1}$ (Vitamim mix) & 0,100 \\
\hline L-lisina $\mathrm{HCl} 98 \%$ (lysine $\mathrm{HCl}$ ) & 0,060 \\
\hline Mist. mineral $^{2}$ (Mineral mix) & 0,050 \\
\hline Cloreto de colina (Choline chloride) & 0,020 \\
\hline $\mathrm{BHT}^{3}$ & 0,010 \\
\hline DL-metionina $99 \%$ (methionine) & 0,000 \\
\hline \multicolumn{2}{|l|}{ Composição (Composition) } \\
\hline Proteína bruta $(\%)^{4}$ & 14,20 \\
\hline \multicolumn{2}{|l|}{ Crude protein } \\
\hline $\mathrm{EM}(M E) \mathrm{kcal} / \mathrm{kg}^{5}$ & 2.751 \\
\hline $\mathrm{Ca}(\%)^{4}$ & 3,98 \\
\hline P total $(\%)^{4}$ & 0,582 \\
\hline \multicolumn{2}{|l|}{$P$ Total } \\
\hline Fósforo disponível $(\%)^{5}$ & 0,385 \\
\hline \multicolumn{2}{|l|}{ Available phosphorus } \\
\hline Metionina $(\%)^{5}$ & 0,235 \\
\hline \multicolumn{2}{|l|}{ Methionine } \\
\hline Metionina digestível $(\%)^{5}$ & 0,211 \\
\hline \multicolumn{2}{|l|}{ Digestible methionine } \\
\hline Metionina + Cistina $(\%)^{5}$ & 0,484 \\
\hline \multicolumn{2}{|l|}{ Methionine + Cystine } \\
\hline Metionina+Cistina digestível (\%) & 0,441 \\
\hline \multicolumn{2}{|l|}{ Digestible methionine + cystine } \\
\hline Lisina $(\%)^{5}$ (Lysine) & 0,731 \\
\hline Lisina digestível $(\%)^{5}$ (Lysine digestible) & 0,642 \\
\hline \multicolumn{2}{|c|}{ 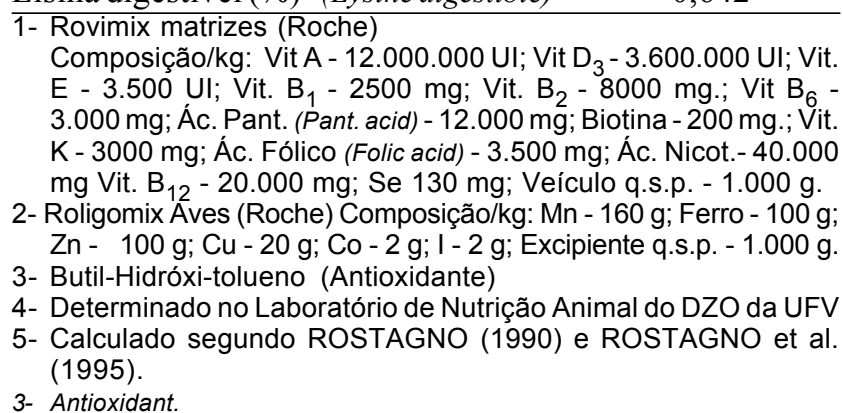 } \\
\hline
\end{tabular}

atribuída ao aumento excessivo deste na ração, promovendo, assim, imbalanço dos demais aminoácidos, como sugerem HARPER (1956) e HARPER et al. (1970). SCHUTTE et al. (1983) também observaram diminuição na taxa de postura, quando aumentaram o nível de metionina acima do normal. Esta afirmação não ficou evidente nos resultados encontrados e não explica consistentemente os resultados.

NARVÁEZ SOLARTE (1996) verificou efeito da 
marca comercial $(\mathrm{P}<0,05)$ sobre esta característica, sendo que as poedeiras leves mostraram-se superiores às poedeiras semipesadas, com médias de massa de ovo diária de 52,09 e 47,06 g, respectivamente.

Foi verificado efeito quadrático $(\mathrm{P}<0,05)$ dos níveis de metionina+cistina sobre a massa de ovo, para as duas marcas comerciais, como pode ser observado na Figura 2.

CALDERON e JENSEN (1990) e NARVÁEZ SOLARTE (1996) relatam também resultados semelhantes em aves alimentadas com rações à base de milho e farelo de soja, suplementadas com metionina+cistina, quando comparadas às alimentadas com rações que não receberam suplementação. Estes resultados, contudo, diferem dos encontrados por SCHUTTE et al. (1983), que não verificaram maior massa de ovo, utilizando diferentes níveis de metionina+cistina.

Para a característica peso médio dos ovos, as poedeiras semipesadas apresentaram maior peso médio $(67,08 \mathrm{~g})$ que o das poedeiras leves $(66,10 \mathrm{~g})$.

Observou-se efeito quadrático $(\mathrm{P}<0,05)$ dos níveis de metionina+cistina sobre o peso médios dos ovos, independente da marca comercial das poedeiras, como pode ser observado na Figura 3.

Estes resultados estão de acordo com os encontrados por HARMS e RUSSEL (1993), SCHUTTE et al. (1994) e NARVÁEZ SOLARTE (1996), os quais relatam que a suplementação de metionina+cistina na ração influenciou positivamente o peso médio dos ovos. RODRIGUES et al. (1995), utilizando poedeiras de segundo ciclo, também obtiveram maiores pesos

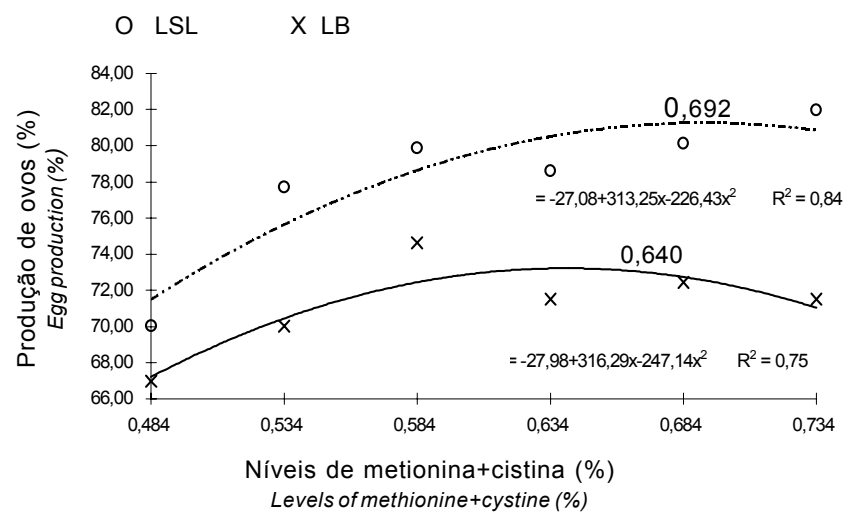

Figura 1 - Efeito dos níveis de metionina+cistina sobre a produção de ovos de poedeiras de ovos brancos (LSL) e ovos marrons (LB), no período de 82 a 97 semanas de idade.

Figure 1- Effect of methionine+cystine levels on the egg production of white-egg (LSL) and brown-egg layers, from 82 to 97 weeks of age. médios de ovos para aves que receberam maiores níveis de metionina+cistina. PETERSEN et al. (1983) obtiveram resultados semelhantes e sugeriram o controle da ingestão de metionina+cistina para controle do peso médio dos ovos.

Foi observada diferença significativa $(\mathrm{P}<0,05)$ entre o consumo de ração para as marcas comerciais leve e semipesada, que apresentaram consumos médio de 113,42 e 116,21 g/ave/dia, respectivamente.

O consumo de ração não foi influenciado significativamente pelos níveis de metionina + cistina, para a marca comercial semipesada. Para a marca comercial leve, observou-se efeito quadrático $(\mathrm{P}<0,05)$ dos níveis de metionina+cistina, conforme Figura 4.

COLNAGO et al. (1985) não verificaram diferença no consumo de poedeiras leves, no segundo ciclo de produção, alimentadas com rações contendo diferentes níveis de metionina + cistina.

Por sua vez, WALDROUP e HELLWING (1995) encontraram que as aves que receberam o menor nível de metionina+cistina apresentaram menor consumo de ração, diferindo dos resultados obtidos por SCHUTTE et al. (1994), em que as aves que receberam o menor e maior nível de metionina+cistina apresentaram maior consumo.

Os maiores consumos foram observados no nível de $0,634 \%$, para poedeiras semipesadas, com consumo diário por ave de $121 \mathrm{~g}$. Para poedeiras leves, o maior consumo foi observado nas aves que receberam ração contendo $0,584 \%$ de metionina+cistina, com consumo diário por ave de $116 \mathrm{~g}$. Estes resultados eqüivalem ao consumo de $16,56 \mathrm{~g}$ de $\mathrm{PB} / \mathrm{dia} /$ ave

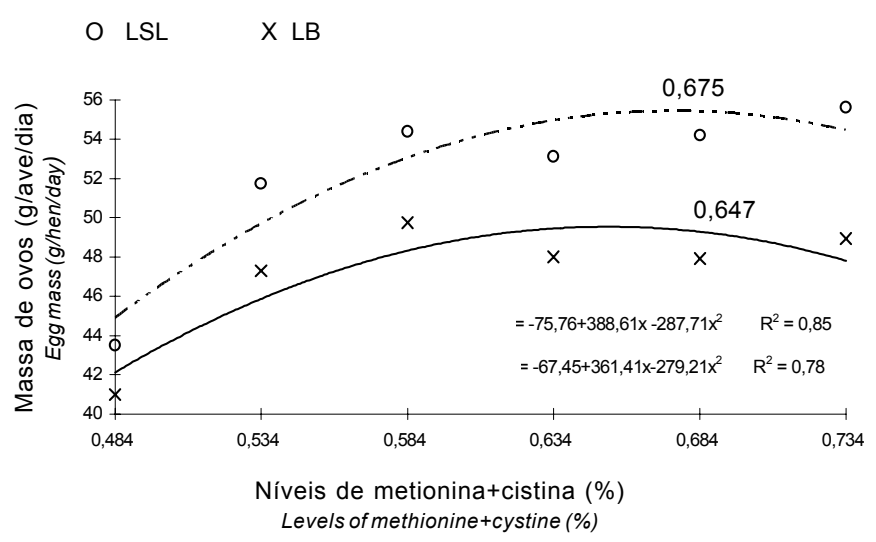

Figura 2 - Efeito dos níveis de metionina+cistina sobre a massa de ovo de poedeiras de ovos brancos (LSL) e ovos marrons (LB)s, no período de 82 a 97 semanas de idade.

Figure 2- Effect of methionine+cystine levels on the egg mass of white-egg (LSL) and brown-egg layers, from 82 to 97 weeks of age. 
para poedeiras leves e 17,42 g de $\mathrm{PB} /$ ave/dia para poedeiras semipesadas.

NARVÁEZ SOLARTE (1996) concluíram que o maior consumo de ração das aves que receberam rações com níveis mais baixos de metionina+cistina é explicado pela ação reguladora do consumo pela metionina, proposta por CHEE e POLIN (1978), em função da variação da magnitude dos níveis de metionina+cistina, produzindo imbalanço aminoacítico, alterando o perfil aminoacítico plasmático do animal e ativando os mecanismos reguladores do apetite.

A diminuição do consumo das aves que receberam ração com níveis mais baixos de metionina+cistina causou redução no consumo de proteína bruta e do próprio aminoácido, agravando possível deficiência de metionina+cistina.

Houve efeito significativo $(\mathrm{P}<0,05)$ da marca comercial sobre a conversão alimentar. As poedeiras semipesadas apresentaram média superior às poedeiras leves, sendo 2,250 para conversão alimentar g de ração/g de ovos produzidos para poedeiras leves e 2,428 para poedeiras semipesadas.

Houve efeito quadrático $(\mathrm{P}<0,05)$ dos níveis de metionina+cistina sobre a conversão alimentar expressa em g de ração/g de ovos produzidos pelas aves de ambas as marcas comerciais, sendo as melhores conversões observadas nas aves que tiveram suplementação de metionina+cistina na ração.

Estes resultados de melhoria na conversão alimentar são semelhantes aos encontrados por SCHUTTE et al. (1983), KUANA et al. (1988) RODRIGUES et al. (1996) e NARVÁEZ SOLARTE et al. (1996). Este efeito deve-se ao melhor equilíbrio aminoacítico da ração.

$\mathrm{Na}$ Tabela 5, são apresentadas as equações de predição das exigências nutricionais em metionina+cistina, determinadas por regressão quadrática, visando melhor produção e massa de ovo, peso médio de ovos e conversão alimentar.

$\mathrm{Na}$ Tabela 6, é apresentado o resumo das exigências nutricionais em metionina+cistina total, digestível e exigência em $\mathrm{mg} / \mathrm{dia}$, para algumas características produtivas.

A exigência de metionina + cistina digestível verdadeira foi estimada por meio da metionina+cistina total e da digestibilidade verdadeira da metionina+cistina, segundo ROSTAGNO et al. (1996).

Considerando as respostas de desempenho das poedeiras e as características avaliadas, respeitandose o ajuste estatístico, bem como a interpretação biológica, pode-se sugerir, para poedeiras no segundo ciclo de produção de 82 a 97 semanas de idade, exigência de 0,692 e $0,655 \%$ de metionina+cistina na ração, correspondendo a consumo diário de 782 e $760 \mathrm{mg}$ de metionina+cistina/ave/dia, para poedeiras leves e semipesadas, respectivamente.

Em termos de metionina+cistina digestível, as poedeiras leves requerem $731 \mathrm{mg}$ de metionina+cistina digestível na ração e as semipesadas, $711 \mathrm{mg}$ de metionina+cistina na ração.

As exigências encontradas neste trabalho foram superiores às encontradas por NARVÁEZ SOLARTE (1996), ROSTAGNO et al. (1996), ZOLLITSCH (1996) e NRC (1994), que utilizaram poedeiras em

Tabela 3 - Efeito de níveis de metionina+cistina (Met+Cis) sobre a produção de ovos, o peso médio dos ovos e a massa de ovo em poedeiras de ovos brancos (LSL) e ovos marrons (LB), no segundo ciclo de produção

Table 3 - Effect of methionine+cystine levels (Meth+cys) on the egg production, egg weight and egg mass of white-egg (LSL) and brownegg $(L B)$ layer hens in the second cycle of production

\begin{tabular}{|c|c|c|c|c|c|c|}
\hline $\begin{array}{l}\text { Nívelde } \\
\text { meth. + cys. (\%) }\end{array}$ & \multicolumn{2}{|c|}{$\begin{array}{c}\text { Produção de ovos }{ }^{2}(\%) \\
\text { Egg production }\end{array}$} & \multicolumn{2}{|c|}{$\begin{array}{c}\text { Peso dos ovos } \\
\text { Egg weight }\end{array}$} & \multicolumn{2}{|c|}{$\begin{array}{l}\text { Massa de ovo }{ }^{2} \text { (ave.dia) } \\
\text { Egg mass (bird.day) }\end{array}$} \\
\hline Level of meth + cys & $\mathrm{LSL}^{1}$ & $\mathrm{LB}^{1}$ & $\mathrm{LSL}^{1}$ & $\mathrm{LB}^{1}$ & $\mathrm{LSL}^{1}$ & $\mathrm{LB}^{1}$ \\
\hline 0,484 & 70,06 & 66,98 & 60,83 & 61,17 & 43,50 & 40,99 \\
\hline 0,534 & 77,71 & 70,03 & 68,11 & 67,30 & 51,72 & 47,28 \\
\hline 0,584 & 79,89 & 74,63 & 67,38 & 68,91 & 54,40 & 49,76 \\
\hline 0,634 & 78,61 & 71,50 & 66,95 & 68,58 & 53,12 & 47,99 \\
\hline 0,684 & 80,14 & 72,45 & 65,91 & 67,67 & 54,18 & 47,91 \\
\hline 0,734 & 81,97 & 71,50 & 67,42 & 68,82 & 55,64 & 48,43 \\
\hline Média & $78,06 \mathrm{a}$ & $71,18 b$ & $66,10 \mathrm{~b}$ & $67,08 \mathrm{a}$ & $52,09 \mathrm{a}$ & $47,06 b$ \\
\hline
\end{tabular}

Mean

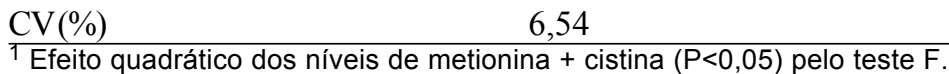

2 Médias da mesma característica, seguidas por letras diferentes, diferem pelo teste $F(P<0,05)$

1 Quadratic effect of levels of methionine + cystine $(P<.05)$ by $F$ test.

2 Means of same characteristics, followed by different letters, differ by $F$ test. 
BARBOSA et al.

Tabela 4 - Efeito de níveis de metionina+cistina (Met+Cis) sobre o consumo de ração e a conversão alimentar em poedeiras de ovos brancos (LSL) e ovos marrons (LB), no segundo ciclo de produção

Table 4 - Effect of methionine+cystine (Met+Cys) levels on the feed intake and feed: egg ratio of of white-egg (LSL) and brown-egg (LB) layer hens, in the second cycle of production

\begin{tabular}{|c|c|c|c|c|}
\hline \multirow[t]{2}{*}{$\begin{array}{l}\text { Nível de met. }+ \text { cis. }(\%) \\
\text { Level of meth }+ \text { cys }\end{array}$} & \multicolumn{2}{|c|}{$\begin{array}{c}\text { Consumo de ração (g/ave/dia) } \\
\text { Feed intake (g/bird/day) }\end{array}$} & \multicolumn{2}{|c|}{$\begin{array}{c}\text { Conversão alimentar ( } \mathrm{g} \text { de ração/g de ovo })^{2} \\
\text { Feed:gain ratio }(g \text { diet } / g \text { egg })\end{array}$} \\
\hline & $\mathrm{LSL}^{1}$ & $\mathrm{LB}^{3}$ & LSL $^{1}$ & $\mathrm{LB}^{1}$ \\
\hline 0,484 & 109,25 & 108,25 & 2,497 & 2,670 \\
\hline 0,534 & 116,00 & 112,50 & 2,190 & 2,455 \\
\hline 0,584 & 114,25 & 116,00 & 2,160 & 2,313 \\
\hline 0,634 & 115,00 & 121,00 & 2,265 & 2,403 \\
\hline 0,684 & 114,25 & 119,00 & 2,213 & 2,360 \\
\hline 0,734 & 111,75 & 120,50 & 2,175 & 2,365 \\
\hline Média & $113,42 b$ & $116,21 \mathrm{a}$ & $2,250 \mathrm{~b}$ & $2,428 \mathrm{a}$ \\
\hline $\mathrm{CV}(\%)$ & \multicolumn{2}{|c|}{3,53} & \multicolumn{2}{|c|}{6,53} \\
\hline
\end{tabular}

${ }^{1}$ Efeito quadrático dos níveis de metionina+cistina $(\mathrm{P}<0,05)$ pelo teste $\mathrm{F}$.

2 Médias da mesma característica, seguidas por letras diferentes, diferem pelo teste $F(P<0,05)$.

3 Efeito não-significativo dos níveis de metionina+cistina $(P>0,05)$ pelo teste $F$.

${ }^{1}$ Quadratic effect of levels of methionine+cystine $(P<.05)$ by $F$ test.

${ }^{2}$ Means of same characteristics, followed by diferent letters, differ by $F$ test.

${ }^{3}$ Non significant effect of levels of methionine+cystine $(P>.05)$, by $F$ test.

Tabela 5 - Regressão das diferentes características em relação ao nível de met+cis, para poedeiras de ovos brancos (LSL) e ovos marrons (LB)

Table 5 - Regression of different traits on the met+cys levels for of white-egg (LSL) and brown-egg (LB) layer hens

\begin{tabular}{|c|c|c|}
\hline & $\begin{array}{c}\text { Poedeiras de ovos brancos } \\
\text { White-egglayers }\end{array}$ & $\begin{array}{c}\text { Poedeiras de ovos marrons } \\
\text { Brown-egg layers }\end{array}$ \\
\hline Produção de ovos & $\hat{\mathrm{Y}}=-27,08+313,25 \mathrm{x}-226,43 \mathrm{x}^{2}\left(\mathrm{r}^{2}=0,84\right)$ & $\hat{\mathrm{Y}}=-27,98+316,29 \mathrm{x}-247,14 \mathrm{x}^{2}\left(\mathrm{r}^{2}=0,75\right)$ \\
\hline Egg production & & \\
\hline Massa de ovo & $\hat{Y}=-75,76+388,61 x-287,71 x^{2}\left(r^{2}=0,85\right)$ & $\hat{Y}=-67,45+361,41 x-279,21 x^{2}\left(r^{2}=0,78\right)$ \\
\hline Egg mass & & \\
\hline $\begin{array}{l}\text { Peso médio dos ovos } \\
\text { Average egg weight }\end{array}$ & $\hat{Y}=-37,41+326,83 x-249,86 x^{2}\left(r^{2}=0,83\right)$ & $\hat{Y}=-21,07+276,43-214,79 x^{2} \quad\left(r^{2}=0,57\right)$ \\
\hline $\begin{array}{l}\text { Conversão alimentar ( } \mathrm{g} \text { de ração/g de ovo) } \\
\text { Feed:egg ratio ( } g \text { diet/g egg) }\end{array}$ & $\hat{Y}=6,01-11,79 x+9,01 x^{2}\left(r^{2}=0,60\right)$ & $\hat{Y}=6,91-14,00 x+10,69 x^{2}$ \\
\hline
\end{tabular}

Tabela 6 - Exigência nutricional de metionina+cistina para produção, massa de ovo, peso médio e conversão alimentar de poedeiras de ovos brancos (LSL) e ovos marrons (LB)

Table 6 - Nutritional requirement of methionine+cystine for production, egg mass, egg weight and feed:egg ratio of white-egg (LSL) and brown-egg (LB) layer hens

\begin{tabular}{|c|c|c|c|c|}
\hline \multirow[t]{2}{*}{$\begin{array}{l}\text { Característica } \\
\text { Trait }\end{array}$} & \multicolumn{4}{|c|}{$\begin{array}{l}\text { Poedeiras leves } \\
\text { White-egg layers }\end{array}$} \\
\hline & $\begin{array}{c}\% \\
\text { Met }+ \text { Cis } \\
\text { total } \\
\text { Meth }+ \text { Cys (total) }\end{array}$ & $\begin{array}{c}\% \\
\text { Met+Cis dig. } \\
\text { Meth }+ \text { Cys }\end{array}$ & $\begin{array}{c}\mathrm{mg} \mathrm{de} \mathrm{Met} \\
+\mathrm{Cis} / \mathrm{dia} \\
m g \\
M e t h+C y s / \text { day }\end{array}$ & $\begin{array}{c}\text { mgde } \\
\mathrm{Met}+\mathrm{Cis} \\
\mathrm{dig} / \mathrm{dia} \\
m g \\
\text { Meth+Cys|day }\end{array}$ \\
\hline $\begin{array}{l}\text { Produção de ovos } \\
\text { Eggproduction }\end{array}$ & 0,692 & 0,649 & 782 & 731 \\
\hline $\begin{array}{l}\text { Massa de ovo } \\
\text { Egg mass }\end{array}$ & 0,675 & 0,632 & 763 & 713 \\
\hline $\begin{array}{l}\text { Peso médio dos ovos } \\
\text { Average egg weight }\end{array}$ & 0,654 & 0,611 & 739 & 691 \\
\hline $\begin{array}{l}\text { Conversão alimentar (g de ração/g de ovo) } \\
\text { Feed:egg ratio ( } \mathrm{g} \text { diet/g egg) }\end{array}$ & 0,655 & 0,612 & 740 & 692 \\
\hline & \multicolumn{4}{|c|}{$\begin{array}{c}\text { Poedeiras semipesadas } \\
\text { Brown-egg layers }\end{array}$} \\
\hline $\begin{array}{l}\text { Produção de ovos } \\
\text { Egg production }\end{array}$ & 0,640 & 0,597 & 742 & 694 \\
\hline $\begin{array}{l}\text { Massa de ovo } \\
\text { Egg mass }\end{array}$ & 0,647 & 0,604 & 751 & 701 \\
\hline $\begin{array}{l}\text { Peso médio dos ovos } \\
\text { Average egg weight }\end{array}$ & 0,643 & 0,600 & 746 & 698 \\
\hline $\begin{array}{l}\text { Conversão alimentar (g de ração/g de ovo) } \\
\text { Feed:egg ratio (g diet/g egg) }\end{array}$ & 0,655 & 0,612 & 7,60 & 711 \\
\hline
\end{tabular}


532 Rev. bras. zootec.
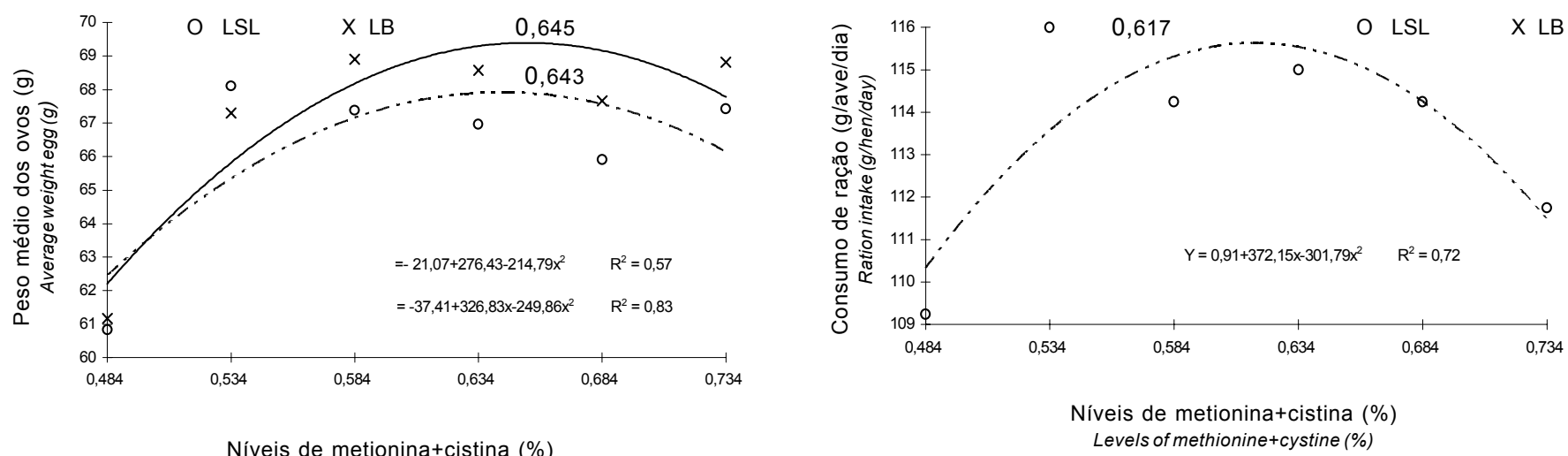

Figura 3 - Efeito dos níveis de metionina+cistina sobre o peso médio dos ovos de poedeiras de ovos brancos (LSL) e ovos marrons (LB), no período de 82 a 97 semanas de idade.

Figure 3 - Effect methionine+cystine levels on the egg weigth of white (LSL) and brown-egg layer, from 82 to 97 weeks of age.

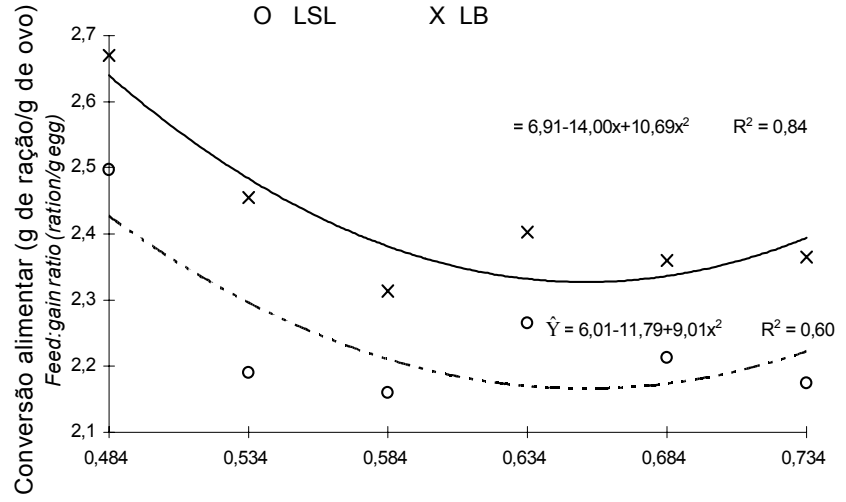

Níveis de metionina+cistina (\%) Levels of methionine+cystine (\%)

Figura 5 - Efeito dos níveis de metionina+cistina sobre a conversão alimentar de poedeirasde ovos brancos (LSL) e ovos marrons (LB), no período de 82 a 97 semanas de idade.

Figure 5 - Effect methionine+cystine levels on the feed: egg ratio of white-egg (LSL) and brown-egg layer, from 82 to 97 weeks of age.

primeiro ciclo para estimar as exigências, e maiores também que as encontradas por COLNAGO (1985) e RODRIGUES (1996), que utilizaram poedeiras em segundo ciclo de produção, porém, esses autores utilizaram outra marca poedeiras comerciais.

Ao contrário do esperado, as poedeiras semipesadas foram menos exigentes que as leves, possivelmente por apresentarem produção de ovos e massa de ovos diário inferiores às poedeiras leves.
Figura 4 - Efeito dos níveis de metionina+cistina sobre o consumo de ração de poedeiras de ovos brancos (LSL) e ovos marrons (LB), no período de 82 a 97 semanas de idade.

Figure 4 - Effect methionine+cystine, levels on the intake of white (LSL) and brown-egg layer, from 82 to 97 weeks of age.

\section{Conclusões}

As exigências nutricionais de metionina + cistina foram estimadas em 0,692 e $0,655 \%$ para poedeiras leves e semipesadas, respectivamente, correspondendo a consumos diários de 0,795 e 0,799 g de metionina+cistina/ave.

\section{Referências Bibliográficas}

BLAIR, R., LEE, D.J., FISHER, C. et al. 1976. Response of laying hens to a low-protein diet supplemented whit essential amino acids, L-glutamic and/or intact protein. Br. Poult. Sci., 17:427-440.

CALDERON, V.M., JENSEN, L.S. 1990. The requeriments for sulfur amino acid by laying hens as influenced by the protein concentration. Poult. Sci., 69:934-944.

CARMO, M.B. Niveis de proteina e de aminoácidos sulfurosos em rações de galinhas poedeiras sob regime de alta temperatura. Viçosa, MG: UFV, 1981. 104 p. Dissertação (Mestrado em Zootecnia) - Universidade Federal de Viçosa, 1981.

CHEE, K.M., POLIN, D. 1978. Effect of methionine and methods of feeding on feed intake. Poult. Sci., 57:1126.

COLNAGO, G.L. Níveis de metionina para galinhas poedeiras no segundo ciclo de produção. In: CONGRESSO BRASILEIRO DE AVICULTURA, 9, 1986, Brasília, DF. Anais... Brasília, 1985, p.61-62.

EUCLYDES, R.F. Manual de utilização do programa SAEG (Sistema para análise estatística e genética). Viçosa, UFV, 1983. 59p.

HARMS, R.H., RUSSELL, G.B. 1993. Optimizing egg mass with amino acid supplementation of a low-protein diet. Poult.Sci., 72:1892-1896.

HARPER, A.E., BENEVENGA, N.J., WOHLHUETER, R.M. 1970. Effects of ingestion of disproportionate amounts of 
amino acids. Phisiological Reviews, 50(3):428-540.

HARPER, A.E. 1956. Amino Acid imbalances, toxicities and antagonisms. Nutritional Reviews, 14:225-227.

KUANA, S., SOARES, P.R., ROSTAGNO, H.S. et. al. 1988. Exigências de energia metabólica e de metionina+cistina para galinhas reprodutoras pesadas. R. Soc. Bras. Zootec., 17(4):385-400.

MYANO, O.A. Viabilidade econômica da muda forçada em poedeiras comerciais. In: CONFERÊNCIA APINCO DE CIÊNCIA E TECNOLOGIA AVÍCOLAS, 6, 1993, Santos. Anais... Campinas: FACTA, 1993. p.159-166.

NATIONAL RESEARCH COUNCIL - NRC. 1994. Nutrient Requirements of Poultry. 9. ed. Washington, D.C. National Academy Press, 155p.

NARVÁEZ SOLARTE, W.V. Exigências em metionina + cistina para poedeiras leves e semipesadas. Viçosa, MG:UFV, 1996. 57p. Dissertação (Mestrado em Zootecnia)- Universidade Federal de Viçosa, 1996.

OLIVEIRA, B.L. Pontos críticos do manejo de poedeiras. In: CONFERÊNCIA APINCO DE CIÊNCIA E TECNOLOGIA AVÍCOLAS, 5, 1992, Santos. Anais... Campinas: FACTA, 1992. p.137-144.

OLIVEIRA, B.L. Alimentação de poedeiras leves após muda forçada. In: SIMPÓSIO LATINO AMERICANO DE NUTRIÇÃO DE AVES, 1993, Campinas. Anais... Campinas: CBNA, 1993. p.46-50.

PETERSEN, C.F., SAUTER, E.A., STEELE, E.E. et al. 1983. Use of methionine intake restriction to improve egg shell quality by control of egg weight. Poult. Sci., 62(10):2044-2047.

RODRIGUES, P.B., BERTECHINI, A.G., DE OLIVEIRA, B.L. et al. 1996. I - Fatores nutricionais que influenciam o desempenho e a qualidade do ovo de poedeiras comerciais no segundo ciclo de produção. I- Níveis de aminoácidos totais. R. Soc. Bras. Zootec., 25(2):248-260.

ROSTAGNO, H.S., SILVA, D.J., COSTA, P.M.A. et al. 1983. Composição de alimentos e exigências nutricionais de aves e suínos: Tabelas Brasileiras. Viçosa, MG: Universidade Federal de Viçosa. 59p.

ROSTAGNO, H.S. Valores de composição de alimentos e exigência nutricional utilizadas na formulação de rações para aves. In: REUNIÃO ANUAL DA SOCIEDADE BRASILEIRA DE ZOOTECNIA, Piracicaba, SP, 1990. Anais... Piracicaba: FEALQ. 1990. p.11-30.
ROSTAGNO, H.S., BARBOZA, W. 1995. Biological efficacy and absorption of DL-methionine hidroxy analogue free acid cpmpared to DL-methionine in chickens as affected by heat strees. Br. Poult. Sci., 36:303-312.

ROSTAGNO, H.S., PUPA, J.M., PACK, M. 1995. Diet formulation for broilers based on total versus digestible aminoacids. J. Appl. Poult. Res., 4:293-299.

ROSTAGNO, H.S., BARBARINO JR, P., BARBOZA, W.A. Exigência nutricional das aves determinadas no Brasil. In: SIMPÓSIO INTERNACIONAL SOBRE EXIGÊNCIAS NUTRICIONAIS DE AVES E SUÍNOS, Viçosa, MG, 1996. Viçosa. Anais... Viçosa: UFV, 1996. p.361-388.

SCHUTTE, J.B., VAN WERDEM, E.J., BERTRAM, H.L. 1983. Sulfur amino acid requeriment of laying hens and the effects of excess methionine on laying performance. $\mathrm{Br}$. Poult. Sci., 24:319-326.

SCHUTte, J.B., JONG, J., BERTRAM, H.L. 1994. Requeriments of the laying hen for sulfur amino acids. Poult. Sci., 73:274-280.

WEERDEN, E. J. V., SCHUTTE, J.B. 1980. Lysine requeriments of the laying hen. Archieve Geflugelk, 44(1):36-40.

WALDROUP, P.W., HELLWING, H.M. 1995. Methionine and sulfur amino acid requirements influenced by stage of production. J. Applied Poult. Res., 4:283-292.

ZOLlitsCH, W., CAO, Z., COON, G. et al. Nutrient requirements of laying hens. In: SIMPÓSIO INTERNACIONAL SOBRE EXIGÊNCIAS NUTRICIONAIS DE AVES E SUÍNOS, Viçosa, MG, 1996. Anais... Viçosa: UFV, 1996. p.109-159.

Recebido em: $12 / 02 / 98$

Aceito em: 03/11/98 